\title{
E-Learning for Elementary Students: The Web 2.0 Tool Google Drive as Teaching and Learning Practice
}

\author{
Angeliki Apergi ${ }^{1}$, Angeliki Anagnostopoulou ${ }^{2} \&$ Alexandra Athanasiou ${ }^{3, *}$ \\ ${ }^{1}$ Elementary Schools of Messinia Division, Peloponnese Prefecture, Greece \\ ${ }^{2}$ Messinia Division, Peloponnese Prefecture, Greece \\ ${ }^{3}$ Hellenic Open University, Patras, Greece \\ *Correspondence: Hellenic Open University, 57 Pontou St., Elliniko, Athens, Greece. Tel: 1- 30-6977-609-562. \\ E-mail: alexalko@otenet.gr
}

Received: February 16, 2015

Accepted: March 23, $2015 \quad$ Online Published: April 29, 2015

doi:10.5430/wje.v5n3p1

URL: http://dx.doi.org/10.5430/wje.v5n3p1

\begin{abstract}
It is a well-known fact that during recent years, the new economic and technological environment, which has emerged from the dynamic impacts of globalization, has given rise to the increased development of information and communication technologies that have immensely influenced education and training all over Europe. Within this framework, there is an ever growing need for educators worldwide to effectively prepare their students for the associated technological and social challenges; something that in reality will constitute the springboard towards achieving future employment and social welfare. It thus becomes evident that technology in the new pedagogies is pervasive and is used as a means for discovering and implementing the deeper learning goals, namely those relating to the creation of new knowledge in the world. In relation to the above, the present study focuses on the impact of the New Pedagogies as perceived through the $21^{\text {st }}$ century skills prism which are highly relevant to students' future academic progress so as for them to achieve, on a long-term basis, personal and professional excellence. Specifically, in the context of creating new knowledge by using the power of digital tools, a case study which explores the exploitation of the web 2.0 Google Drive tool in $6^{\text {th }}$ graders' classes (elementary school) within Project-based learning $(\mathrm{PBL})$ framework is examined. The research is expected to prove that the involved German educator is going to assist her students via a promising PBL activity so as for them to realize the value of ICT in the learning process.
\end{abstract}

Keywords: e-learning; web 2.0 tools; google drive; $21^{\text {st }}$ century skills; project-based learning; new pedagogies

\section{Introduction}

\subsection{New Pedagogies and $21^{\text {st }}$ Century Skills}

It is apparent in our days, as Papaefthymiou - Lytra (2010:8) claims, that globalization and the development of Information and Communication Technologies (ICT) have significantly influenced education and training. European citizens as well as citizens all over the globe find themselves in constant need "to acquire new skills and update their knowledge and expertise". Consequently, this new economic and technological environment has already given rise to alternative educational and training practices. In particular, as stated in Sifakis (2010:12-13), the widespread use of new technologies is likely to "offer cooperative learning opportunities between instructors and learners and/or among learners" while simultaneously providing them with "more opportunities for improving problem solving capabilities, enhancing high order thinking skills, and achieving learning effectiveness".

In the light of the aforementioned, Fullan \& Langworthy (2014:3) claim that while in the old pedagogies a teacher's performance was assessed primarily in terms of his or her ability to deliver content in their area of specialization, in the new pedagogies the foundation of teacher quality is a teacher's pedagogical capacity - their repertoire of teaching strategies and their ability to form partnerships with students in mastering the process of learning. However, in spite of the fact that the digital revolution has already transformed the way young people and children play, learn, communicate and access information, as Fullan \& Langworthy (2014:7) indicate, it has not so far "transformed most 
schools or most teaching and learning in classrooms". Towards completion of the digital update of typical as well as non typical educational streams, there is a pressing need for both the expansion and development of New Pedagogies which will most probably focus not only on literacy and numeracy in the context of the 'eight key competences' as stated by the European council (Athanasiou, Anagnostopoulou, 2013:86) but also on such new challenges as "problem-solving, collaboration, creativity, thinking in different ways, and building effective relationships and teams" (Fullan \& Langworthy, 2014:7).

These New Pedagogies are not just modern teaching/learning strategies but in essence constitute effective teaching/learning models which challenge students to create new knowledge and connect it to the world by using the power of digital tools as well as the strength of the learning partnerships emerging among them, their classmates and their teachers. Apart from students' and teachers' partnering, in order to process the assigned learning tasks as well as the employment of digital tools toward the achievement of this goal, 'deep learning tasks' constitute another important element of the new pedagogies which aim "to engage students in practicing the process of deep learning through discovering and mastering existing knowledge and then creating and using new knowledge in the world" (Fullan \& Langworthy, 2014:21). As defined in Bell (2014:4), "PBL is an approach to instruction that teaches curriculum concepts through a project... guided by an inquiry question that drives the research and allows students to apply their acquired knowledge". According to the same writer Project-based Learning (PBL) revolves around vital parameters for its success such as:

- Students' learning to be Self-Reliant through Planning and Organization

- Social Learning which Enhances Collaboration Skills

- Differentiated Instruction which Provides Intrinsic Motivation

- Use of Technology which Enhances Creativity within Parameters such as safety and effectiveness

- Real-world connections

- Creating success from the beginning (some sort of learning contract)

In addition to the aforementioned, PBL is described as an approach in which students and the teacher constitute a unified group working towards the completion of a learning goal; As aptly pointed out in Larmer \& Mergendoller (2011:1), PBL is not "a typical unit of instruction" in which on the one hand a teacher uses multiple teaching methods such as a combination of lectures, worksheets, textbook readings, video programs as well as website visits and on the other hand the students are given assignments while at the same time "the unit culminates with a test emphasizing factual recall" (Larmer \& Mergendoller (2011:2). On the contrary, PBL approach is a "main course" (ibid) Project- Based Learning in which students learn the material by completing the project, i.e. from the process not from the product. In this framework, a "main course" project:

- is intended to teach significant content

- requires critical thinking, problem solving, collaboration, and various forms of communication

- requires inquiry as part of the process of learning and creating something new

- $\quad$ is organized around an open-ended Driving Question

- creates a need on the part of the students/trainees for comprehension of essential content and skills

- allows some degree of student voice and choice

- includes processes for revision and reflection

- involves a public audience

and is likely to render a multidisciplinary dimension to the project in the form of a learning partnership either in typical or non-typical educational streams (Anagnostopoulou \& Athanasiou, 2013:211,212). Simultaneously, PBL activities seem to be more meaningful if students conduct real inquiry through the project implementation phase as Larmer \& Mergendoller (2012:3) illustrate. In this way, students receive plenty of practice in solving real-world problems via, apart from the above mentioned qualities, "a good driving question which captures the heart of the project in clear, compelling language" (ibid).

As has been previously discussed, although new technologies in the modern pedagogical era are prevalent and are used to create new knowledge, the digital revolution has not yet transformed classroom teaching and learning to a level where modern pedagogy can accommodate its full capacity. As Light et al claim (2010:5), although "Web 2.0 applications have tremendous potential to transform students' learning", such Web 2.0 tools as "Facebook, MySpace, 
wikis, and blogs are part of nearly every student's home life, these technologies are barely used in school". As explained in Light et al (2010:7), the term web 2.0 applications, used on a daily basis within the teaching/learning procedure, refers to both "a large and shifting set of technological tools" as well as "an approach to the socially and technologically integrated use of technology" in the framework of the social dimension of project-based learning which, by nature, enhances collaboration.

Within the aforementioned framework, web 2.0 applications are likely to steadily guide us to a new form of learning featured by segregation, selection, organization and managing of the abundance of incoming information, all of which are based on collaborative, learner- centered and active learning procedures as well as individualized and differentiated teaching/learning approaches, all taking into account student needs and interests (Stefanidis et al, 2013:628). In terms of using web 2.0 tools in project-based learning (PBL), the case study which will be described in the next part of this research, aims at highlighting the social and technological dimensions of project-based learning, which focus on the sharing, creation and editing of documents by multiple users both collaboratively and asynchronously.

\section{Method: Web 2.0 Application -based Case Study in Action}

\subsection{Google Drive within PBL Framework}

In the second part of the present research, there is an endeavor on the part of the involved educator to concurrently address, apart from skills-building (learning math facts \& basic literacy), the life-skills (e.g. communication \& collaboration) needed to succeed in our rapidly changing world (Mattern et al, 2014:4) via a case study which took place in an elementary school. In connection to the educator's effort, students' familiarization with project-based learning (PBL) by means of the Google Drive web 2.0 tool constitutes an indispensable prerequisite in order for dynamic teaching scenarios, in which students take on an essentially creative and active role in producing knowledge, to be implemented. It became evident during the case study that, as students' ability to act for themselves improved (digital literacy, autonomous learning, critical analysis and synthesis of information), students' need for guidance on the part of the educator decreased significantly.

Within this framework, the present research focused on a PBL activity implemented in two classes of $6^{\text {th }}$ graders who studied the fall of the Berlin Wall by means of the Google Drive Web 2.0 Tool. Specifically, Google Drive and its potential to provide users with the capability to create collaborative presentations, was selected so as for aspects pertaining to the active participation of students, their adjustment to a complex learning environment as well as the promotion of collaborative and multicultural learning in the context of teaching German as a foreign language (FL) to be practiced. Two classes of $6^{\text {th }}$ graders, approximately 40 elementary school students, took part in the present PBL case study. Pupils of elementary schools are taught German for two (2) hours a week and can be classified in level A2 according to the Common European Framework of Reference (CEFR). A dynamic scenario in line with Project-based learning (PBL) including ICT (Information Communication Technology) use was designed and put into effect titled "The Wall of Berlin- from Marlene Dietrich to... the Wall of Berlin today". Blended learning was followed as a teaching/learning method (face-to-face collaborative teaching/ learning as well as distance collaborative teaching/learning through Google Drive by means of comments and feedback)

\subsection{Project Implementation Stage}

The Projcect - based Learning (PBL) implementation model with Google Drive presentation and its tools comprised the following stages:

\subsubsection{Preparation}

During the preparation project phase, students participated in negotiating the PBL aims with the teacher, proposing the project theme as well as the preferred teaching/learning strategies. A discussion took place regarding the anticipated benefits as well as the selection of Google Drive as a web tool for information search and the creation of web presentations. Students watched examples of Google Drive presentations and a conversation followed dealing with the prospect of collaborative creation of content and text, blended learning activities, communication and participation, synchronous and asynchronous communication, commentary and feedback. Moreover, students were able to self- search the tool and get accustomed to particular assets such as content process, feedback and commentary, insertion of videos, images, hyperlinks, dictionary and charts, controlled access via the appearance of the review record, possibility for the incorporated webquest tool as well as chatting. The learning contract among the educator and the pupils, in which generic and specific ICT use rules referring to individual as well as team communication via Google Drive, was deemed essential and therefore has also been reported as constituting part of 
the process. Furthermore, discussions with students who had learning difficulties or that did not have access to computers (digital gap) were also conducted. The project span was discussed as well whereas students were invited to bring forward their ideas on the topic of the specific project.

\subsubsection{The Topic}

Project driving questions such as which theme would be of interest to the students or in which ways would students prefer to participate during the selection of the project topic or which theme would intrigue all students constituted the commencement of the project. The integration of the Berlin Wall theme at the beginning of the school year guided everyone involved toward the selection of this topic. Students had already watched videos and presentations, listened to songs relative to the history of the wall and concluded to the final selection of the theme namely "The Wall of Berlin- from Marlene Dietrich to... the Wall of Berlin today"

\subsubsection{The Plan}

The chosen theme related to individual aspects of the topic which constituted the object of negotiation within the project groups. Following Oakley's et al (2004:3) criteria for team formation according to which forming teams “... whose members are diverse in ability levels and who have common blocks of time to meet outside class as well as avoid isolating at-risk minority students on teams", the project groups under discussion were shaped based on students' literacy and digital competence level, their gender and their preferences. In pedagogic terms, it was considered significant for students with various abilities to be represented in groups so as for mutual support from both genders as well as group balance to be ensured. In this context, six groups were formed as follows:

- The first group was assigned the task of searching for information about Marlen Ditrich

- The second group studied historic details about the two German states that were created in 1948 (Bundesrepublik Deutschland - BDR \& German Democratic Republik - DDR or GDR)

- The third group was assigned the task of searching for information about the Berlin Wall

- The fourth group investigated Bertolt Brecht

- The fifth group studied factual data about Stasi (the Ministry of the federal safety of Eastern Germany)

- The sixth group went on a virtual tour around Berlin to discover wall ruins

More specifically, one student from each team opened a Google Drive presentation, titled it, e.g. Bertolt Brecht and shared the document with the rest of the team members as well as the educator. During a regular teaching session (45 min.), the teams convened with a view to determining the way they would prefer to approach the topic associated with the Berlin Wall, they made proposals, assigned activities to group members and conversed, whenever necessary, with the teacher. Moreover, the project schedule was examined by means of the blended learning method (synchronously and asynchronously).

\subsubsection{The Research, the Information Quest and the Implementation}

In this stage, each group worked on the presentation they had opened in Google Drive and used the incorporated Google Drive webquest tool. Both the students and the teacher were able to make comments, ask for clarifications and questions and provide answers as well as highlight issues pertaining to the learning process. Communication among group members took place asynchronously and this constitutes the main reason why the term Asynchronous Distance Learning is used in this case study. During implementation, each team communicated via the Google Drive (GD) common presentation as well as during the group sessions. The students processed the information collected on the topic, posed inquiries, assisted one another and discussed the content as well as the form of the final presentation. The educator provided the necessary technical support while at the same time systematically monitored the GD use. She offered learning support as well as simultaneous feedback and also reinforced both technically and cognitively, students that displayed low levels of participation. What is more, the students and the teacher were responsible for maintaining the web learning contract they had already agreed upon in earlier stages.

\section{Results}

\subsection{Project Dissemination and Evaluation}

Students of both classes of $6^{\text {th }}$ graders who worked on this project were granted the opportunity to present the outcome of their teams' collaboration by means of Google Drive use in two parts. First, each group presented their work in class while the rest of the groups asked questions and commented on the answers provided. Secondly, representatives of the involved groups contributed to the day seminar held under the title "Web 2.0 Tools in Foreign 
Language Teaching within Public Schools" not only by disseminating their work to the foreign language teachers attending it but they also coordinated a teacher training innovation. According to this innovation, students indicated new teaching/learning methods since, to this date, foreign language teachers had been basically trained via public organizations according to face-to-face training models (Anagnostopoulou \& Apergi, 2013: 1, 2). More specifically, students of the involved teams assigned one of their classmates the task to coordinate the seminar via "training" the teachers on the use of Google Drive in connection to foreign language teaching thus introducing the notion of online teacher training and/or alternative methods of project-based teaching/learning for students.

In relation to the above, the student - coordinator emphasized, with the educator's assistance, the pedagogical characteristics as well as benefits deriving from the use of the Google Drive tool in the learning process. The involved educator, who implemented the aforementioned assignment with her elementary students, also mentioned the ways in which students evaluated the specific learning experience by highlighting the difficulties associated with collaborative learning methods in conjunction with the insecurity some students experienced as they were confronted with a totally new learning experience. Even so, during the learning process, students displayed a positive attitude and participated with higher levels of enthusiasm and greater interest as it becomes evident from their reported claim "...we felt closer to one another". In addition, reinforcement of student collaboration, development of critical thinking and problem solving skills, familiarization with a web tool and distance learning principles, more effective organization of learning material and improved dissemination of the project's final outcome can be considered as very important pedagogical benefits. Finally, every group presented the final product resulting from their collaboration to the teachers of this seminar and answered posed inquiries.

As has been mentioned above, the project under consideration had already been evaluated by the students and the teacher during the first part of dissemination (the in-class presentation) through discussion according to the following modular pillars:

- What did we learn from one another in terms of new knowledge and life-skills?

- Which added pieces of incoming information and knowledge did we acquire?

- Which teaching/learning methods did we follow, with our teacher's guidance and facilitation, during the conduct of our involvement in our project and why?

- Which were the gained pedagogical and cognitive benefits?

- How did I (on a personal level) evaluate the work of my team as well as the overall work of the rest of the groups?

- How did the teacher evaluate the work of all the teams involved in the project?

The discussion, conducted with the elementary students involved in the PBL activity under consideration and based on the aforementioned modular pillars, constituted, in reality, the foreshadowed (indicated/suggested) questions of a nonstructured interview which is "more conversationlike and allows for the greatest flexibility. The researchers may simply jot down a list of topics that they want to cover in the interview" as Lodico, Spaulding \& Voegtle (2006:124,266) state. The German language teacher of the elementary students, who participated in the case study under investigation, took down the above queries which were later answered and further analyzed by students with the teacher monitoring the whole process at the same time providing students with valuable feedback. This feedback was granted by means of effective probes, i.e. follow-up questions which were asked in order to get clarification about the students' responses (Lodico, Spaulding \& Voegtle, 2006:125) on the main modular pillars referred to above. The probes, activated by the educator, was further extended by student comments thus taking the form of an essential discussion among students themselves as well as the teacher as a member of a unified PBL group leading to substantial reflection on the specific PBL activity procedure as well as the students' acquired skills.

\section{Discussion}

The specific paper discussed the new pedagogies and their important constituents such as communication, collaboration, problem- solving, team work, creativity as well as use of ICT through Project -based learning. Given the technological and social changes of our times, students and teachers are invited to embrace the growing development of modern technological tools already in use by the majority of students at their homes and in their everyday lives. Taking this parameter into account, the present study focused on two teaching/learning pillars, ICT use within a project-based teaching/learning environment as well as the implementation of $21^{\text {st }}$ century skills which constitute essential learning tools for $21^{\text {st }}$ century students. In this framework, a case study which involved young 
students completing the first six years of compulsory education (elementary school) is presented.

The elaborated case study referred to the conduct of a PBL activity in the context of German as a foreign language in a public school via the use of the Google Drive (GD) Web 2.0 Tool. Specifically, elementary school $6^{\text {th }}$ graders used Google Drive to collaboratively work with their classmates on a group project relating to the fall of the Berlin wall without their constant presence in face-to-face sessions, while their teacher concurrently provided immediate feedback on students' provided work. Realizing the need for the acquisition of $21^{\text {st }}$ century skills, namely collaboration, communication, team building, problem solving, critical thinking, creativity as well as autonomous learning, the involved German language teacher decided to propose a different activity to her students: a dynamic ICT scenario in agreement with the Project-based Learning (PBL) method.Students negotiated syllabus with their teacher and ended up with an agreement on studying "The Wall of Berlin-from Marlene Dietrich to... the Wall of Berlin today" topic via using the Google Drive (GD) Web 2.0 Tool.

On the initiation of the project, the teacher posed a number of questions which, on the one hand, constituted the driving force of the teaching/learning procedure while on the other hand the core of the unstructured interview she held with her pupils in a conversationlike mode. Later, she negotiated the project theme as well as the teaching/learning strategies with her students in detail gradually reaching a decision on the project topic as well as proceeding with the selection of the web 2.0 tool; after they had watched a number of sample Google Drive (GD) presentations in order to experience the actual use of the tool, they concluded to the Google Drive as an asynchronous distance learning mode which essentially assisted them in creating collaborative presentations. Then, the division of 6 project groups took place according to criteria which would ensure groups effectiveness.

In the above described context, each of the project groups was assigned to study online and finally prepare a Google Drive (GD) presentation of one sub-topic under the thematic umbrella of the fall of the Berlin Wall. In addition, on the completion of their presentations, students had to receive their classmates' feedback, reflect on it and make possible alterations before finally presenting their work in a teacher training event in which one of the students had to stand up to a teachers' audience, analyze the teaching/learning procedures they had followed as well as the assets of the Web 2.0 Tool they had used. The feedback the students received by their classmates (during the first project evaluation phase of the in-class presentation) as well as the teachers (during the second project evaluation phase of the teacher training day-seminar), was invaluable as it led them to meta-knowledge, i.e not only the realization of their cognitive level regarding the Berlin Wall history or the use of ICT, but also the ability to reflect on their learning modes as well as work together and learn from each other. The presentation and dissemination of the specific PBL activity finally proved the value of the new learning philosophy in modern pedagogy which has begun to prevail in schools thus equipping students with new skills deemed indispensable for their lives as active citizens in the $21^{\text {st }}$ century.

\section{Acknowledgements}

We wish to extend our gratitude to all stakeholders of the project titled "E-Learning for Elementary Students: The Web 2.0 Tool Google Drive Exploited by Students as Learning and Teaching Practice" which was implemented in a Greek elementary school including:

- the learners of the elementary school who participated in the German - Greek taught project

- the German language teacher who was inspired by the idea of using ICT tools in class

- the colleagues of the elementary school who provided assistance by allowing students to participate in the project for additional hours

- the School Principal who catered for the use of specialized equipment of the project class

The support, perseverance and commitment of the above mentioned parties have led to the realization of this vision into a tangible reality.

\section{References}

Anagnostopoulou, A., \& Apergi, A. (2013). “Digital Foreign Language Class in Practice: FL Teacher Training” pp 1324 - 1330 in Education in the ICT Era 19 -20/10. Athens: Ministry of Education.

Anagnostopoulou, A., \& Athanasiou, A. (2013). An overview of lifelong learning practices, with an emphasis on the 'Grundtvig' action. Research Papers in Language Teaching and Learning, 4(1), 207-2017. 
Athanasiou, A., \& Anagnostopoulou, A. (2013). The Impact of Grundtvig Learning Partnerships on Educating and Training the European Workforce. English Linguistics Research, 2(2), 86-95. http://dx.doi.org/10.5430/elr.v2n2p86

Bell, S. (2014). Project-Based Learning for the 21st Century: Skills for the Future. London: Routledge.

Berger, R. (2014). Beautiful Work. Retrieved 03/07/2014 from www.bie.org

Common European Framework of Reference for Languages: Learning, Teaching, Assessment (CEFR). Retrieved 20/09/2014 from http://www.coe.int/t/dg4/linguistic/cadre1_en.asp

Fullan, M., \& Langworthy, M. (2014). A Rich Seam - How New Pedagogies Find Deep Learning. UK: Pearson.

Larmer, J., \& Mergendoller, J. (2012). 8 Essentials for Project-Based Learning. CA: ASCD.

Larmer, J., \& Mergendoller, J., R. (2011). The Main Course, Not Dessert: How Are Students Reaching 21st Century Goals? With 21st Century Project Based Learning. Buck Institute for Education. Retrieved from www.bie.org

Light, D., \& Polin Keisch, D. (2010). Integrating Web 2.0 tools into the classroom: Changing the culture of learning. NY: EDC.

Lodico, M. G., Spaulding, D. T., \& Voegtle, K., H. (2006). Methods in Educational Research: From Theory to Practice. San Franscisco CA: Jossey-Bass.

Mattern, M., Sridhar Sethi, R., \& Texeira, E. (2014). Right to Play: "A Case Study on the Application of $21^{\text {st }}$ Century Skills Harvard Graduate School of Education". Retrieved 20/09/2014 from http://isites.harvard.edu/fs/docs/icb.topic1377845.files/Right\%20to\%20Play\%20Case\%20Study\%20-\%20Mega $\mathrm{n} \%$ 20RashikaTexeira.doc

Oakley, B., Brent, R., Felder, R. M., \& Elhajj, I. (2004). Turning Student Groups into Effective Teams. Journal of Student Centered Learning, 2(1), 9-34.

Papaefthymiou - Lytra, S. (2010). "ICT, Lifelong Learning, Cultural Diversity and Adult Learners: What Educators Should Know" p.p 6-10 in ICT and Lifelong Learning in all Types of Education: Does this Promote Cultural Diversity? Proceedings of the ecoMEDIA - Europe 2010 annual conference Kalamata: K.A.N.E.

Sifakis, N. (2010). "Lifelong Learning, E-learning and Professional Development: Challenges and Opportunities for Greek Foreign Language Teachers" p.p 11-17 in ICT and Lifelong Learning in all Types of Education: Does this Promote Cultural Diversity? Proceedings of the ecoMEDIA - Europe 2010 annual conference Kalamata: K.A.N.E.

Stefanidis Y., Kakkou S., Psaromiligos I., \& Spiridakos, A. (2013). "Exploitation of Web 2.0 tools in Elementary Education” p.p. 627 - 635 in Education in the ICT Era conference. Athens: Elementary Educators' Scientific Union for the Dissemination of the ICT. 